\title{
ТЕСТ-СИСТЕМЫ ПЦР ДЛЯ ВЫЯВЛЕНИЯ ГЕНОМА КАПРИПОКСВИРУСОВ И ВИРУСА ЗАРАЗНОГО УЗЕЛКОВОГО ДЕРМАТИТА
}

\author{
А.В. СПРЫГИН, Я.Е. ПЕСТОВА, Е.С. КОСТРОВА, С.В. КОНОНОВА, \\ О.П. БЬЯДОВСКАЯ, Т.В. ЖБАНОВА, А.В. КОНОНОВ
}

\begin{abstract}
Интенсификация животноводства неизбежно повышает риски заноса и распространения инфекционных заболеваний, из которых наиболее опасны трансграничные. Инфекции крупного рогатого скота, вызываемые каприпоксвирусами, в частности вирусом заразного узелкового дерматита (ЗУД, Lumpy skin disease, LSD), поражают крупный и мелкий рогатый скоту, нанося существенный экономический ущерб. До 2015 года территория Российской Федерации была благополучна по ЗУД, однако из-за локальных конфликтов на Ближнем Востоке и изменений климата заболевание распространяется в северном направлении (масштабные вспышки LSD в Tyрции, странах Балканского полуострова, ЕС и в России). Широкое использование живых гомологичных вакцин против LSD в соседних странах также актуализирует разработку методов диагностики этого возбудителя, позволяющих выявлять геномы полевых изолятов и дифференцировать вакцинный вирус ЗУД КРС. Нами впервые в России разработан и валидирован комплекс методов ПЦР в режиме реального времени для однорежимного тестирования проб на наличие генома каприпоксвирусов, полевых изолятов вируса заразного узелкового дерматита и вакцинного вируса ЗУД KPC типа Neethling. На основе выравнивания полногеномных последовательностей идентифицированы сайты, наиболее пригодные для специфичной амплификации при выявлении генома полевых изолятов, вакцинных штаммов и каприпоксвирусов. Для амплификации фрагмента генома полевых изолятов мы выбрали участок ORF126 гена $E E V$ вируса LSD - вставку размером 27 п.н., отсутствующую у других представителей рода Capripoxvirus и вакцинных штаммов типа Neethling. Для амплификации фрагмента генома вакцинных штаммов использовали участок ORF008, в котором присутствуют уникальные замены, характерные только для таких штаммов, для каприпоксвирусов - участок гена P32, консервативный для всех представителей рода Capripoxvirus. Предложенные методы показали высокую чувствительность (98 \%), специфичность (99\%) и адекватную повторяемость (коэффициент вариации не более 2 \%). Апробацию тест-систем проводили на панели из 596 проб биологического материала, собранного при вспышках каприпоксвирусных инфекций в России, - стабилизированной крови, сыворотки крови, соскобов кожи (нодулы), назальных и окулярных смывов, молока, тканей лимфатических узлов, легких, трахеи, селезенки и абортплодов, отобранных от животных, инфицированных в естественных условиях. Следует отметить, что с помощью разработанного комплекса тест-систем ПЦР-РВ в рамках мониторингового исследования на заразный узелковый дерматит в ряде регионов Российской Федерации отмечены случаи выявления генома вакцинного вируса ЗУД КРС. Это может свидетельствовать либо о нелегальном использовании запрещенной к ввозу в Россию аттенуированной живой вакцины типа Neethling, либо о естественном распространении вакцинного Neethling. На основе разработанных методов оформлено два патента РФ на изобретения, что подтверждает оригинальность и значимость предложенных методик для диагностических исследований.
\end{abstract}

Ключевые слова: заразный узелковый дерматит, нодулярный дерматит, вакцинный штамм, каприпоксвирус, ПЦР, Neethling.

Заразный узелковый дерматит (нодулярный дерматит) крупного рогатого скота (Lumpy skin disease, LSD) - трансграничная инфекционная болезнь крупного рогатого скота (KPC), которая проявляется повышением температуры тела, образованием кожных узлов (бугорков), при генерализации инфекционного процесса - лимфаденитом, поражением конъюнктивы, слизистых оболочек органов дыхания и пищеварения (1-4). Возбудитель LSD - ДНК-содержащий оболочечный вирус из семейства Poxviridae рода Capripoxvirus, к которому отнесены родственные этому вирусу возбудители оспы овец и оспы коз (5). Геном вируса представлен двуцепочечной ДНК длиной 151 тыс. п.н. (6).

Заболеванию подвержен крупный рогатый скот и буйволы (7), среди КРС наиболее уязвимы коровы молочного направления, при этом заболеваемость может колебаться от 3 до $80 \%$ (3, 8-10), что свидетельствует 
о возможной роли других, еще не изученных факторов, влияющих на тяжесть клинических признаков. Согласно данным литературы, самым распространенным путем передачи инфекции считается заражение через укусы кровососущих насекомых $(11,12)$ и клещей $(13,14)$, однако однозначно вектор пока не установлен. Все вспышки LSD с клиническими признаками инфекции подлежат обязательной нотификации в Международном эпизоотическом бюро (МЭБ, Office International des Epizooties, OIE, Франция). В настоящее время по данным МЭБ вспышки инфекции зафиксированы в Албании, Болгарии, Греции, Сербии, Турции и других странах (15-19). В России болезнь впервые зарегистрирована в 2015 году (20), а в 2016 год в 16 субъектах на территории страны отмечено 313 вспышек инфекции, главным образом в Центральном федеральном округе (21). В 2017-2018 годах вспышки начали регистрировать в Приволжском федеральном округе вблизи от государственной границы Российской Федерации (22).

Живые гомологичные вакцины против LSD на основе аттенуированного вакцинного штамма Neethling активно используются в приграничных странах (как на территории Казахстана, так и в ЕС). Поэтому необходим комплекс методов для выявления и дифференциации возбудителей каприпоксвирусных инфекции, в том числе идентификации вакцинного штамма Neethling, который также способен вызывать клинические проявления болезни у животных $(23,24)$. Помимо LSD, в России представляет опасность оспа овец, периодически регистрируемая на Дальнем Востоке. В 2015 году вспышку этого заболевания отмечали уже в Северо-Кавказском регионе России, а в 2016-2018 годах - на территории Центрального федерального округа (22). С учетом беспрецедентного распространения вируса LSD, в том числе субклинического переболевания $(25,26)$, требуются высокочувствительные методы диагностики, позволяющие проводить мониторинг среди латентно инфицированных восприимчивых животных для быстрого выявления генома возбудителя, борьбы с инфекций и предотвращения ее распространения.

В этом сообщении нами впервые предложены чувствительные и специфичные тест-системы ПЦР-РВ для однорежимного (имеющего одинаковый температурный профиль) тестирования проб на наличие генома каприпоксвирусов (ПЦР-CAPR), полевых изолятов вируса заразного узелкового дерматита (ПЦР-LSDV) и вакцинного штамма LSD (ПЦР-NEE).

Целью исследования была разработка комплекса методов ПЦР в режиме реального времени, позволяющих выявлять геномы и дифференцировать всех представителей рода Capripoxvirus, полевые изоляты вируса LSD и вакцинный штамм типа Neethling в различных биоматериалах.

Методика. Суммарную ДНК выделяли из 100 мкл суспензии биоматериала с помощью набора для выделения нуклеиновых кислот DNA Mini Kit («Qiagen», Германия) согласно инструкции изготовителя.

Для выбора сайтов амплификации и участков отжига зондов в ПЦР проанализировали полногеномные последовательности полевых изолятов виpyca LSD (KX683219, KSGP 0240, KY829023 Evros/GR/15, KY702007 SERBIA/Bujanovac/2016, AF409137 Neethling Warmbaths LW, AF325528 Neethling 2490), вакцинных штаммов (KX764643 SIS-Lumpyvax vaccine, KX764644 Neethling-Herbivac vaccine, AF409138 Neethling vaccine LW 1959, KX764645 Neethling-LSD vaccine-OBP), а также оспы овец и коз (KX576657 Gorgan, KC951854 FZ, AY077836 G20-LKV, AY077835.1 Pellor, AY077833 Sheeppox virus A, AY077832 Sheeppox virus 10700-99 strain TU-V02127, MG000156 Sheeppox virus strain Jaipur, AY077834 Sheeppox virus NISKHI), депониро- 
ванные в базе данных GenBank (https://www.ncbi.nlm.nih.gov/genbank/).

Праймеры и зонды разрабатывали с помощью программного обеспечения Primer3 engine software (http://bioinfo.ut.ee/primer3-0.4.0/) и синтезировали в фирме «Синтол» (г. Москва). В качестве источника флуоресценции применяли краситель FAM (5'-конец зонда); гаситель флуоресценции - BHQ1 (3'-конец зонда). Праймеры и зонд для выявления генома полевых изолятов вируса в системе ПЦР-LSDV описаны ранее (27).

ПЦР в режиме реального времени (ПЦР-РВ, амплификатор Rotor Gene Q 6 plex, «Qiagen», Германия) проводили согласно протоколу: активация при $95{ }^{\circ} \mathrm{C} 10$ мин; 40 циклов - $95{ }^{\circ} \mathrm{C} 15$ с, $60{ }^{\circ} \mathrm{C} 1$ мин. Использовали набор реактивов GoTaq® MDx Hot Start Polymerase («Promega Corp.», США). Реакционная смесь (25 мкл) включала 5 мкл 10× ПЦР-буфера, 3 мкл $25 \mathrm{MM} \mathrm{MgCl}$, 0,5 мкл 10 нмоль dNTP, по 12,5 пмоль прямого и обратного праймеров, 7,5 пмоль зонда. Результаты интерпретировали по тому, пересекается или не пересекается кривая флуоресценции с пороговой линией, что соответствует наличию или отсутствию значения порогового цикла $\mathrm{Ct}$. Образец считали положительным по вирусной ДНК при $\mathrm{Ct} \leq 40$.

Для оценки специфичности тест-системы ПЦР-РВ протестировали с генетическим материалом гомологичных и гетерологичных вирусов. Эксперименты по определению специфичности были поставлены индивидуально с ДНК каждого вируса и в присутствии ДНК нескольких вирусов. Для тестирования и оптимизации разработанных методов использовали ДНК референтных штаммов гетерологичных вирусов из Коллекции штаммов микроорганизмов ФГБУ ВНИИЗЖ, а также ДНК изолятов гомологичных и гетерологичных вирусов, выделенных в различных регионах России. Оценка специфичности системы ПЦР-LSDV описана ранее (27).

Аналитическую чувствительность тест-системы по выявлению генома вакцинного штамма (ПЦР-NEE) определяли с серией 10-кратных раз-

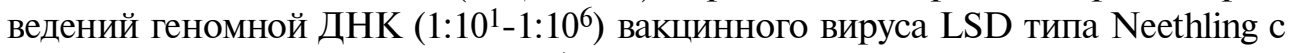
исходным титром 5,21 lg ТЦД 0 /мл, в случае тест-системы для выявления генома каприпоксвирусов (ПЦР-CAPR) использовали препарат вируса оспы овец (штамм Афганский) с титром 6,17 lg ТЦД50/мл. Для статистической верификации полученных результатов и построения линейной регрессии провели три повторных эксперимента с 10-кратными разведениями геномной ДНК. Эффективность амплификации рассчитали согласно формуле: $\mathrm{E}=\left(10^{\text {slope }}-1\right) \times 100 \%$, где $10^{\text {slope }}-$ коэффициент наклона.

Воспроизводимость $(C v, \%)$ результатов определяли по величине стандартного отклонения $( \pm \mathrm{SD})$ для каждой серии разведений, используя полученные значения Ct. Для оценки вариабельности значений порогового цикла один образец тестировали 3 раза в 5-кратной повторности (1 запуск 5 повторений) на протяжении 3 сут. Для каждого запуска (5 повторений) и для всех запусков (15 повторений) рассчитывали средние значения $\mathrm{Ct}$, стандартные отклонения $( \pm \mathrm{SD})$ и коэффициент вариабельности $(C v, \%)$.

Диагностическую чувствительность (ДЧ) и диагностическую специфичность (ДС) тест-систем проверяли на пробах крови и назальных смывах, которые получали от естественно зараженных животных. Значения рассчитывали по следующим формулам: ДЧ $=$ ИП/(ИП + ЛО), где ИП - истинно положительные пробы, ЛО - ложноотрицательные пробы; ДС = ИО/(ИО + ЛП), где ИО - истинно отрицательные пробы, ЛП ложноположительные пробы.

Исследовали 596 проб биологического материала от животных с клиническими признаками заболевания: стабилизированную кровь, сыворотку крови, соскобы кожи (нодулы), назальные и окулярные смывы, мо- 
локо, ткани лимфатических узлов, легкого, трахеи, селезенки, а также абортированные плоды. Анализы проводили на базе референтной лаборатории болезней (ФГБУ ВНИИЗЖ, 2016-2017 годы).

Для обработки значений Сt использовали регрессионный анализ по Пассингу-Баблоку (Passing-Bablok Regression) и метод Блэнда-Алтмана BlandAltman plots), для оценки связи между значениями использовали коэффициент корреляции Лина (Lin's concordance correlation coefficient) (28).

Результаты. Примененные нами праймеры и зонды кратко охарактеризованы в таблице 1. Описание гомологичных и гетерологичных вирусов (референтные штаммы из Коллекции штаммов ФГБУ ВНИИЗЖ, а также изоляты гомологичных и гетерологичных вирусов из разных регионов России, использованные при оценке специфичности тест-систем ПЦРРВ) представлено в таблице 2.

1. Праймеры и зонды для выявления вирусов рода Capripoxvirus и дифференциации генома вакцинного штамма и полевых изолятов вируса LSD в ПЦР-PВ

\begin{tabular}{|c|c|c|c|c|c|}
\hline $\begin{array}{l}\text { Агент (тест- } \\
\text { система) }\end{array}$ & Последовательность $\left(5^{\prime} \rightarrow 3^{\prime}\right)$ & $\begin{array}{l}\text { Прайме- } \\
\text { ры, зрнды }\end{array}$ & Ген & $\begin{array}{l}\text { Ампли- } \\
\text { Кон, п.н. }\end{array}$ & Ссылка \\
\hline Вакцинный вирус & TGTTTCCATTCTCCACTGCT & fnee 3 & \multirow{3}{*}{ LSDV008 } & \multirow{3}{*}{185} & Это \\
\hline \multirow[t]{2}{*}{ ЗУД КРС (NEE) } & ТАСТTАСТАAАAAATGGGCGCA & rnee3 & & & исследо- \\
\hline & TCGCTGACATCGTTAGTCCACTC & Probe & & & вание \\
\hline Каприпоксвирусы & ATGAAACCAATGGATGGGATA & Capr_f & \multirow[b]{2}{*}{ P32 } & \multirow[b]{2}{*}{92} & Это \\
\hline (CAPR) & $\begin{array}{l}\text { CGAAATGAAAAACGGTATATGGA } \\
\text { ATGAGCCATCCATTTTCCAA }\end{array}$ & $\begin{array}{l}\text { Capr_r } \\
\text { Probe }\end{array}$ & & & $\begin{array}{l}\text { исследо- } \\
\text { вание }\end{array}$ \\
\hline Полевой изолят & AGAAAATGGATGTACCACAAATACAG & f2 & \multirow[b]{2}{*}{ EEV } & \multirow{3}{*}{96} & \multirow{3}{*}{ (27) } \\
\hline ЗУД КРС (LSDV) & $\begin{array}{l}\text { TTGTTACAACTCAAATCGTTAGGTG } \\
\text { ACCACCTAATGATAGTGTTTATGATTTACC }\end{array}$ & $\begin{array}{l}\text { r33 } \\
\text { lsdv probe }\end{array}$ & & & \\
\hline & & & & & \\
\hline
\end{tabular}

\section{2. Штаммы и изоляты вирусов, использованные в исследовании}

\begin{tabular}{|c|c|c|c|c|}
\hline \multirow[b]{2}{*}{ Вирус } & \multirow{2}{*}{ Штамм/изолят } & \multirow[b]{2}{*}{ Происхождение/коллекция } & \multicolumn{2}{|c|}{ ПЦР } \\
\hline & & & CAPR & NEE \\
\hline Вирус ЗУД КРС & $\begin{array}{l}\text { ВНД КРС/Дагестан/2015 } \\
\text { (диагностический) }\end{array}$ & Россия/ФГБУ ВНИИЗЖ & + & - \\
\hline Вирус ЗУД КРС & ВНД КРС Э-95 (Д) & Африка/ФГБУ ВНИИЗЖ & + & - \\
\hline Аттенуированный вакцинный штамм & Neethling & ЮAP VRI Onderstepoort/ФГБУ & & \\
\hline LSD & & ВНИИЗЖ & + & + \\
\hline Вирус оспы овец & Афганский & Афганистан/ФГБУ ВНИИЗ & + & - \\
\hline Полевой изолят вируса оспы овец & & Россия (Ярославская обл.)/нет & + & - \\
\hline Вирус оспы коз & Приморский 2003 & Россия/ФГБУ ВНИИЗЖ & + & - \\
\hline Полевой изолят вируса эктимы овец & & Россия/нет & - & - \\
\hline
\end{tabular}

На основе выравнивания последовательностей мы идентифицировали сайты, наиболее консервативные только у полевых изолятов, только у вакцинных штаммов и у всех каприпоксвирусов. Для амплификации участка генома полевых изолятов выбрали рамку считывания LSDV126 для гена $E E V$ вируса нодулярного дерматита, в котором у других представителей семейства Capripoxviridae и вакцинных вирусов типа Neethling делетирован участок 27 п.н., тогда как у полевых изолятов вируса эта вставка присутствует (рис. 1, А). Для амплификации фрагмента генома вакцинных штаммов выбрали участок LSDV008, в которой присутствуют уникальные замены, характерные только для таких штаммов (см. рис. 1, Б). Для амплификации генома каприпоксвирусов был выбран ген P32, консервативный для всех представителей семейства Capripoxviridae (см. рис. 1, В).

Для проверки специфичности метода использовали материал, содержащий ДНК гетерологичных вирусов (вирус чумы мелких жвачных, вирус везикулярного стоматита, вирус эктимы овец, вирус оспы коров). В результате при тестирования диагностической системы с ДНК каждого 
вируса по отдельности, а также со смесью ДНК нескольких вирусов ложноположительных результатов мы не выявили.

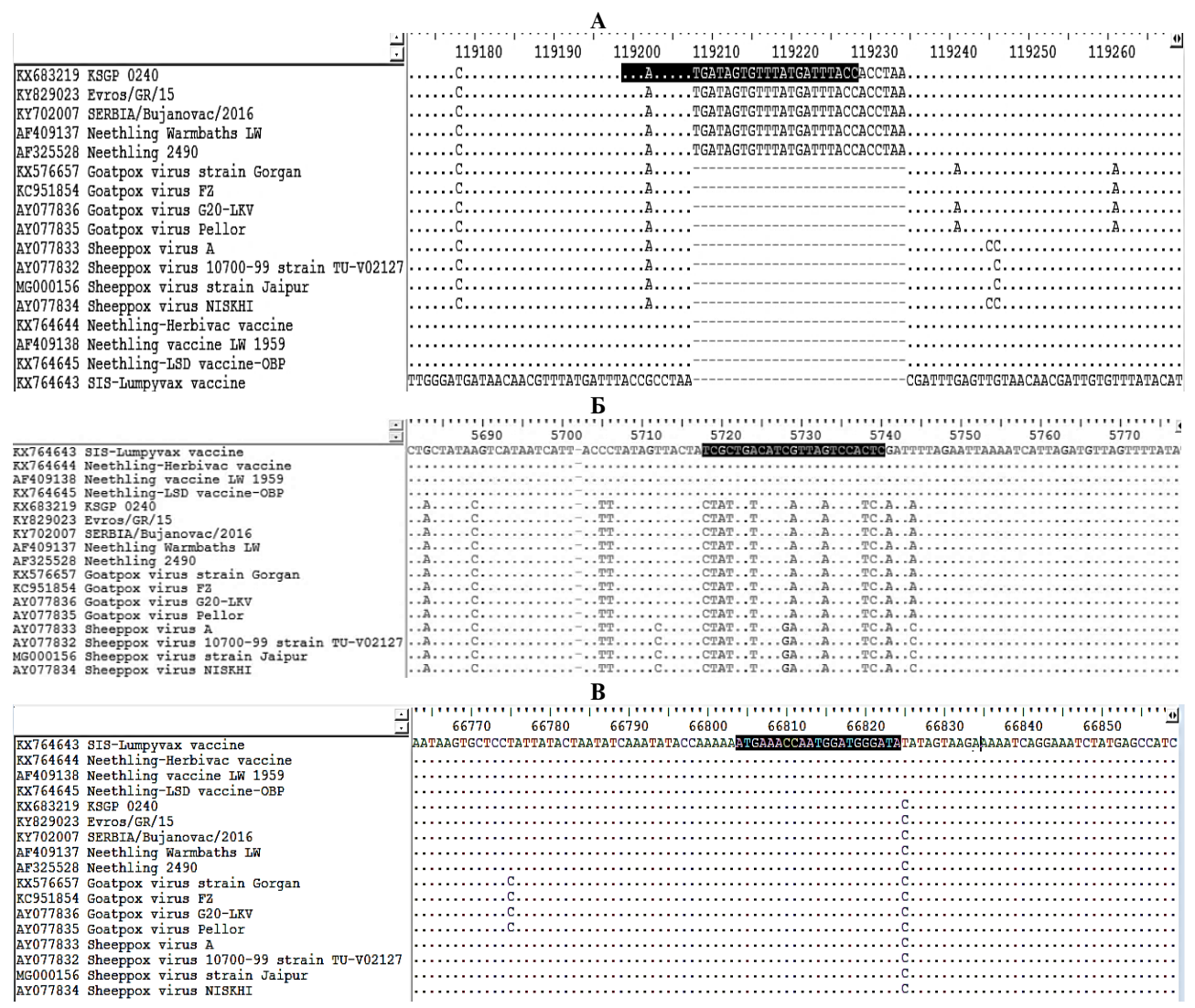

Рис. 1. Зона отжига зонда для выявления полевых изолятов вируса заразного узелкового дерматита крупного рогатого скота (А), вакцинных штаммов этого вируса (Б) и каприпоксвирусов (В) в ПЦР-РВ (см. также на сайте журнала http://www.agrobiology.ru).
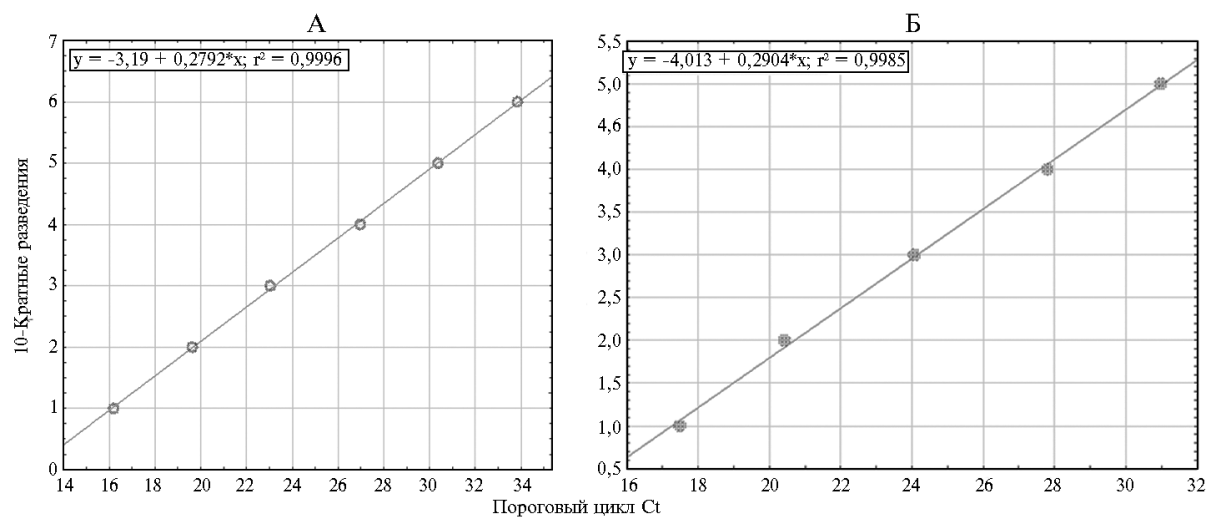

Рис. 2. Графики линейной регрессии значений $\mathrm{Ct}$ при тестировании 10 -кратных разведений ДНК каприпоксвирусов (А) и вакцинного штамма вируса заразного узелкового дерматита (Б) в ПЦРРВ, подтверждающие линейность полученных результатов.

При оценке чувствительности тест-системы ПЦР-CAPR использовали ДНК вируса оспы овец штамма Афганский с титром инфекционной активности 6,17 lg ТЦД 50 мл. Тест-система ПЦР-CAPR (рис. 2, А) выявляла вирусную ДНК с чувствительностью $0,17 \mathrm{lg}$ ТЦД $50 /$ мл. Для оценки эффективности амплификации провели три повторных эксперимента и получили значения $\mathrm{Ct}$, которые использовали для расчета эффективности. На 
основе коэффициента угла наклона, полученного при построения графика линейной регрессии (см. рис. 2, А), значение эффективности амплификации $\mathrm{E}=90,2 \%$. При оценке воспроизводимости результатов для шести последовательных 10-кратных разведений стандартное отклонение SD варьировало от 0,12 до 0,32 .

Чувствительность тест-системы ПЦР-NEE оценивали с использованием ДНК вируса заразного узелкового дерматита вакцинного штамма Neethling с титром инфекционной активности 5,21 lg ТЦД $50 /$ мл. Тест-система выявляла вирусную ДНК с чувствительностью $0,21 \mathrm{lg}$ ТЦД фективность амплификации (см. рис. 2, Б) составила $\mathrm{E}=95,16 \%$. Величина стандартного отклонения SD для тест-системы ПЦР-NEE изменялась от 0,03 до 0,60 для серии из пяти 10-кратных разведений.

Основные количественные характеристики разработанных тест-систем суммирует таблица 3 .

3. Эффективность, величина стандартного отклонения (SD) и коэффициент детерминированности $\left(\mathrm{r}^{2}\right)$ тест-систем ПЦР-РВ для выявления и дифференциации полевых изолятов вируса заразного узелкового дерматита крупного рогатого скота, вакцинных штаммов этого вируса и каприпоксвирусов

\begin{tabular}{l|c|c|c}
\hline \multicolumn{1}{c}{ Тест-система } & Эффективность, \% & SD (min-max) & $\mathrm{r}^{2}$ \\
\hline ПЦР-CAPR & 90,20 & $0,12-0,32$ & 0,999 \\
ПЦР-LSDV & 98,60 & $0,11-0,33$ & 0,990 \\
ПЦР-NEE & 95,16 & $0,03-0,60$ & 0,998
\end{tabular}

П р и м е ч н и е. Описание тест-систем см. в разделе «Методика». По ПЦР-LSDV представлены данные исследования, выполненного ранее (27). таблица 4.

Колебания величины Ct при измерении показателей иллюстрирует

4. Вариабельность значений $\mathrm{Ct}$ для одного-трех запусков при применении тестсистем ПЦР-РВ

\begin{tabular}{|c|c|c|c|}
\hline Тест-система, запуск & Среднее значение $\mathrm{Ct}$ & $\pm \mathrm{SD}$ & $\mathrm{Cv}, \%$ \\
\hline \multicolumn{4}{|l|}{ ПЦР-CAPR $(n=5)$ : } \\
\hline 1-й & 28,80 & 0,23 & 0,79 \\
\hline 2-й & 29,05 & 0,54 & 1,85 \\
\hline 3-й & 29,15 & 0,32 & 1,09 \\
\hline \multicolumn{4}{|l|}{ ПЦР-LSDV $(n=5)$ : } \\
\hline 1-й & 30,01 & 0,43 & 1,43 \\
\hline 2-й & 30,76 & 0,41 & 1,33 \\
\hline 3-й & 29,93 & 0,16 & 0,53 \\
\hline \multicolumn{4}{|l|}{ ПЦР-NEЕ $(n=5)$ : } \\
\hline $1-и ̆$ & 29,56 & 0,37 & 1,20 \\
\hline 2-й & 29,53 & 0,36 & 1,20 \\
\hline 3-й & 30,15 & 0,25 & 0,80 \\
\hline \multicolumn{4}{|c|}{ В среднем по трем запусками $(n=15)$ : } \\
\hline ПЦР-CAPR & 29,00 & 0,39 & 1,34 \\
\hline ПЦР-LSDV & 30,27 & 0,52 & 1,71 \\
\hline ПЦР-NEЕ & 29,76 & 0,50 & 1,60 \\
\hline
\end{tabular}

Результаты сравнения ДЧ и ДС для ПЦР-CAPR и ПЦР-LSDV представлены на рисунке 3. Согласно полученным данным, статистической разницы между значениями $\mathrm{Ct}$ при использовании методик ПЦРCAPR и ПЦP-LSDV мы не выявили (p >0,05). На основе полученных значений $\mathrm{Ct}$ для двух тест-систем коэффициент корреляции Лина между результатами ПЦР-CAPR и ПЦР-LSDV тестов составил 91,3\%.

С использованием трех тест-систем ПЦР-РВ мы исследовали 596 проб биологического материала, полученного от КРС в 2015-2017 годах. Геном вируса LSD был выявлен в 155 пробах, что составило 26,0 \% от общего числа исследованных (табл. 5).

Наиболее часто вирус LSD КРС выявляли в носовых смывах (25,0 \%), 
A

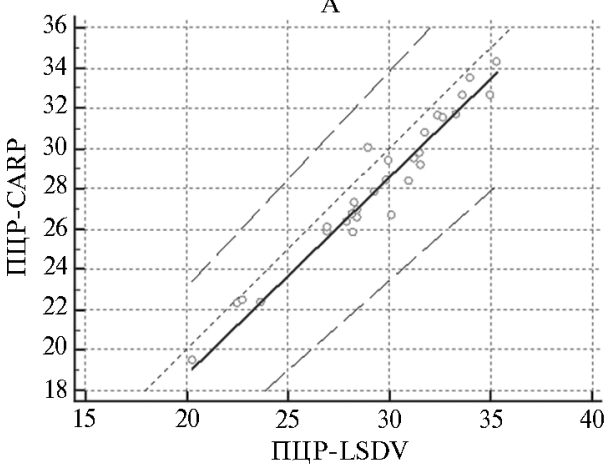

Б

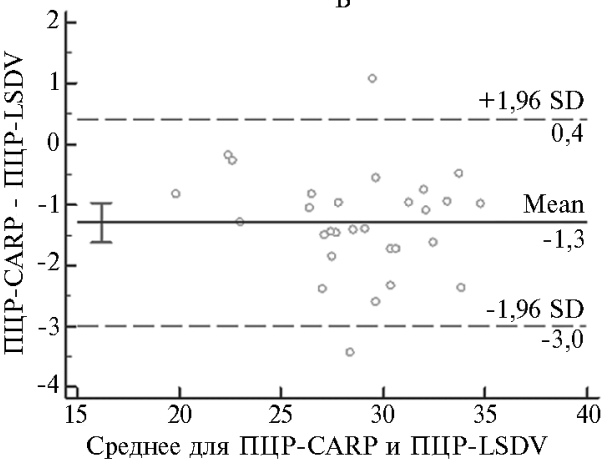

Рис. 3. График регрессии по Пассингу-Баблоку (А) и диаграмма рассеивания по Блэнду-Алтману (Б) для значений $\mathrm{Ct}$ тест-систем ПЦР-CAPR и ПЦР-LSDV при доверительном интервале $95 \%$. Описание тест-систем см. в разделе «Методика».

5. Выявление генома вируса LSD в полевых образцах биоматериала от крупного рогатого скота (20015-2017 годы)

\begin{tabular}{l|c|c|c}
\hline \multirow{2}{*}{\multicolumn{1}{c|}{ Биоматериал }} & \multicolumn{3}{|c}{ Число проб } \\
\cline { 2 - 4 } & \multirow{2}{*}{ всего } & \multicolumn{2}{|c}{ положительных } \\
\cline { 3 - 4 } & & $n$ & $\%$ \\
\hline Нодулы & 95 & 74 & 78 \\
Кровь стабилизированная & 235 & 31 & 13 \\
Сыворотка крови & 117 & 17 & 14,5 \\
Носовые смывы & 104 & 26 & 25 \\
\hline
\end{tabular}

в сыворотке крови $(14,5 \%)$ и стабилизированной крови $(13,0 \%)$. При тестировании патологического материала геном вируса LSD обнаружили в пробах пораженных кожных покровов (нодулах) в $78 \%$ случаев. В образцах трахеи, селезенки и от абортированных плодов геном вируса LSD KРC не выявили. Дополнительно исследовали три пробы молока от КРС с клиническими признаками LSD (в двух обнаружили геном LSDV), пять образцов лимфоидной ткани (два положительных), четыре образца ткани легкого (три оказались положительными по наличию генома LSDV). Совпадение положительных/отрицательных результатов между ПЦР-CAPR и ПЦР-LSDV coставило $100 \%$.

Лабораторная диагностика LSD важна для подтверждения предположительного диагноза и, соответственно, своевременности действий по предотвращению распространения вируса. При этом следует отметить, что биологические и эпизоотологические свойства LSDV изучены недостаточно и требуют более глубокого понимания. Вирусы заразного узелкового дерматита и оспы овец представляют серьезную угрозу животноводству всех стран, включая Российскую Федерацию (21). До 2015 года Россия считалась страной, благополучной по LSD, поскольку исторически LSD ограничивался Африканским континентом и Ближним Востоком (25). Что касается оспы овец, то это заболевание регистрировалось, главным образом, на Дальнем Востоке и Северном Кавказе. Единственным способом борьбы с каприпоксвирусами считается вакцинация, а в случае с LSD вакцинация гетерологичными и гомологичными (аттенуированной) вакцинами (25). Гетерологичная вакцина на основе вируса оспы овец безопасна для КРС, тогда как живые аттенуированные вакцины, например Lumpyvax (ЮАР) и аналогичные ей, при введении животным могут вызывать проявление клинических признаков заболевания (26). Поэтому актуальны методы дифференциальной молекулярной диагностики.

В этом сообщении впервые представлен разработанный комплекс тест-систем ПЦР-РВ, позволяющих одновременно выявлять геномы каприпоксвирусов, полевых изолятов вируса LSD и вакцинного штамма Neethling. 
Преимущество такого подхода заключается в том, что все тесты проводятся с одинаковыми концентрациями компонентов реакции и при одинаковом температурном профиле. Эти тест-системы успешно валидированы с использованием большого числа проб, отобранных как при вспышках заболевания, так и от экспериментально зараженных животных. Полученные при этом результаты подтверждены секвенированием и выделением вируса в культуре клеток (данные не представлены). Все пробы, отобранные при нотифицируемых вспышках LSD на территории Российской Федерации, начиная с 2015 года, были проверены с помощью тест-систем ПЦР-CAPR и ПЦР-LSDV, причем совпадение результатов составило $100 \%$.

Тест-системы ПЦР-CAPR и ПЦР-NEE разработаны в рамках этого исследования, а тест-система ПЦР-LSDV для полевых изолятов описана ранее (27). Все локусы для амплификации и сайты отжига зондов выбирались по критериям консервативности (по всем изолятам, данные по которым доступны в GenBank) и уникальности для обеспечения высокой специфичности (см. рис. 1). Для каждой из разработанных тест-систем ПЦРРВ детекция указанных вирусов стала возможной благодаря уникальности генетических сигнатур.

При одном запуске эффективность амплификации для всех тестсистем в серии из пяти 10-кратных разведениях вирусного материала составляет более $90 \%$, чувствительность - 0,3 $\mathrm{lg}$ ТЦД $50 / \mathrm{cm}^{3}$ (см. табл. 3). Более того, высокая диагностическая чувствительность и специфичность при тестировании с панелью ДНК гомологичных и гетерологичных вирусов делает этот комплекс незаменимым в постановке диагноза при работе с пробами полевого материала. Сравнение результатов ПЦР-CAPR и ПЦР-LSDV показало отсутствие статистически значимых различий между значениями $\mathrm{Ct}$ при тестировании одних и тех же проб (p >0,05), а средняя разница между значениями составляла 1,3 цикла при коэффициенте корреляции Лина 91,3 \% (см. табл. 4). К сожалению, сравнение тестсистем ПЦР-CAPR и ПЦР-NEE не представляется возможным из-за отсутствия достаточно большой выборки проб, содержащих геном вакцинного вируса LSD.

В литературе есть несколько публикаций о методах для выявления геномов каприпоксвирусов, полевого или вакцинного штамма LSDV. Paнее широко использовался классический метод D.C. Ireland и Y.S. Binepal (29) на основе классической ПЦР, однако он не специфичен в отношении конкретного вируса и выявляет все каприпоксвирусы (27). К тому же классическая ПЦР несет риски кросс-контаминации и имеет более низкую чувствительность. Для вариантов ПЦР-РВ в литературе представлены работы по выявлению генома каприпоксвирусов (30), полевых изолятов (31), вакцинного и полевого штамма в формате дуплекс (Duplex PCR, одновременное выявление двух генов-мишеней) (32). Важно отметить, что наши тест-системы ПЦР-LSDV и ПЦР-NEE показали более высокую эффективность - 95,16 и 98,60 \%, чем дуплексная ПЦР в упоминаемой работе (32) - 91,3 и 90,7 \% для соответствующих штаммов.

При оценке специфичности мы использовали изоляты, циркулирующие на территории России, тогда как зарубежные коллеги оценивали специфичность на штаммах, выявленных за пределами нашей страны. Для того чтобы признать какие-либо методы универсальными, необходимо провести кросс-валидацию с включением всех штаммов, детектированных к настоящему времени в мире.

Одновременно преимущество и недостаток метода Е.I. Agianniotaki с соавт. (32) в том, что в одной пробирке можно дифференцировать вак- 
цинный штамм от полевого изолята. В нашем исследовании тест-системы работают независимо в разных пробирках в отличие от дуплекса, где из-за одновременного присутствия обоих вирусов чувствительность реакции снижается. Такая особенность дуплексной ПЦР особенно критична в начале кампании по вакцинации живыми вакцинами в зонах с активной циркуляции полевых штаммов вируса.

Разработанный комплекс ПЦР тест-систем апробирован на 596 пробах биоматериала (образцы различных тканей и органы) от КРС с LSD, зараженного в естественных условиях на территории Российской Федерации в 2015-2017 годах (21) (см. табл. 5). Подчеркнем, что корреляция между результатами тестирования в ПЦР-LSDV и ПЦР-CAPR составила $100 \%$, что подтверждает надежность этих методов для проведения диагностики. Необходимо отметить, что при отборе проб в случае подозрения на LSD должны учитываться и клинически здоровые животные, поскольку они могут быть скрытыми носителями вируса без видимых симптомов (24). Это имеет особое практическое значение, так как надзор над эпизоотической ситуацией по LSD KРC проводится главным образом прижизненно.

Геном вируса LSD наиболее часто регистрировался в нодулах (78 \% проб), что согласуется с результатами других исследовании и подтверждает выраженный тропизм вируса к кожному эпителию (33). К тому же показано, что с помощью ПЦР геном вируса LSD в крови животных обнаруживается с момента появления нодул (33). В наших исследованиях геном вируса LSD в остальных пробах биоматериала выявляли в 13-25 \% проб (см. табл. 5). Генетический материал вируса также выявлялся в тканях легких, лимфоузлов и в молоке, однако из-за ограниченного числа проб статистически оценить эти результаты однозначно пока нельзя. Важно отметить, что пробы от животных поступали в период начала развития клинических признаков, что могло сказаться на результативности выявления вируса LSD. Например, отсутствие генома вируса в большинстве проб смывов, в сыворотке крови и в цельной крови, вероятно, объясняется тем, что вирус еще не успел накопиться в достаточной количестве, чтобы при экскреции в биологические жидкости его концентрация превышала предел чувствительности тест-системы. Более того, S. Babiuk с соавт. (33) установили, что при экспериментальном заражении экскреция вируса слизистыми оболочками может начаться после появления нодул, причем ДНК вируса в смывах детектируется в течение короткого промежутка времени (несколько суток) и в низкой концентрации, виремия тоже кратковременна (9 сут) и характеризуется непостоянством наличия вируса на протяжении эксперимента (33). Эти свойства, возможно, объясняют слабую трансмиссию вируса между животными при отсутствия лёта переносчиков.

Важно отметить, что система ПЦР-NEЕ для тестирования вакцинного штамма, валидированная на таком же объеме материала, позволила выявить несколько случаев возможного нелегального использования вакцины против LSDV на основе штамма Neethling в ряде регионов России (данные не представлены), хотя впервые геном вакцинного штамма Neethling был обнаружен в Республике Башкортостан у коров с клиническими признаками ЗУД КРС (34). Применение живых аттенуированных вакцин против LSDV в РФ запрещено, однако на территории других стран Таможенного Союза (например, в Казахстане) таких ограничений нет, что грозит распространением LSDV по приграничным регионам (34). Результаты выполненного нами секвенирования показали, что выявленный вакцинный вирус и вакцинные штаммы, используемые в коммерческих препаратах аттенуированных гомологичных вакцин, на $100 \%$ гомологичны по 
соответствующему фрагменту гена RPO30 (данные не представлены). При этом совпадение результатов ПЦР-CAPR и ПЦР-NEE составило $100 \%$.

Все результаты, полученные с помощью предложенных нами тестсистем, подтверждены выделением вируса в чувствительной культуре клеток (данные не представлены), что свидетельствует о надежности используемых методов ПЦР-РВ при дифференциации вакцинного штамма и полевого изолята. Высокая степень апробированности и валидации предложенных тест-систем подтверждена оформлением патентной заявки РФ, что также свидетельствует о новизне разработки $(35,36)$.

Таким образом, нами разработаны надежные тест-системы ПЦРPВ для однорежимного тестирования проб на наличие генома каприпоксвирусов, полевых изолятов вируса заразного узелкового дерматита и вакцинного штамма LSDV. Методы показали высокую специфичность и чувствительность при тестировании с панелью проб биоматериала от естественно зараженных животных.

\footnotetext{
ФБГУ Федеральный иентр охраны здоровья животных, 600901 Россия, г. Владимир, мкр. Юрьевец, ФГБУ ВНИИЗЖ, e-mail: spriginav@mail.ru $₫$, pestova@arriah.ru, kostrova@arriah.ru, kononova@arriah.ru, bjadovskaya@arriah.ru, zhbanova@arriah.ru, kononov@arriah.ru
}

\title{
ONE-RUN REAL TIME PCR ASSAYS FOR THE DETECTION OF CAPRIPOXVIRUSES, FIELD ISOLATES AND VACCINE STRAINS OF LUMPY SKIN DISEASE VIRUS
}

\author{
A.V. Sprygin, Ya.E. Pestova, E.S. Kostrova, S.V. Kononova, O.P. Byadovskaya, \\ T.V. Zhbanova, A.V. Kononov
}

Federal Center for Animal Health Control, FGBU VNIIZZh, mkr. Yurievets, Vladimir, 600901 Russia, e-mail spriginav@mail.ru ( $\bowtie$ corresponding author), pestova@arriah.ru, kostrova@arriah.ru, kononova@arriah.ru, bjadovskaya@arriah.ru, zhbanova@arriah.ru,kononov@arriah.ru

ORCID:

Sprygin A.V. orcid.org/0000-0001-5982-3675

Pestova Ya.E. orcid.org/0000-0002-7974-623X

Kostrova E.S. orcid.org/0000-0001-7150-7632

Kononova S.V. orcid.org/0000-0002-3932-2416

The authors declare no conflict of interests

Received September 25, 2018

Byadovskaya O.P. orcid.org/0000-0002-8326-7151

Zhbanova T.V. orcid.org/0000-0002-9857-5915

Kononov A.V. orcid.org/0000-0002-5523-3261

doi: 10.15389/agrobiology.2019.2.347eng

\section{Abstract}

The cattle and sheep industry is economically important for sustainable growth. However, the increasing demand for livestock products drives animal population growth and risks for infection diseases. Lumpy skin disease (LSD) has recently expanded its historical range northward reaching countries that were never affected before. Prior to 2015 the territory of the Russian Federation was free of lumpy skin disease, whereas by 2017 Turkey, Serbia, Greece, Azerbaijan have reported incursions of this virus. Not only lumpy skin disease but also sheep pox has increased in incidence. Given this scenario, timely detection of these pathogens is key towards successful control and eradication. Moreover, diagnostic tools should detect both LSDV genome in the face of the use of live vaccine LSD virus strains and distinguish between the two. In this paper we report the development of a set of one-run real-time PCR assays to detect and differentiate between Capripoxvirus genome, field and vaccine LSD virus genomes. The assay for field LSD virus targets the $27 \mathrm{bp}$ deletion in ORF126, the assay for vaccine LSD virus targets genetic signatures unique to Neethling vaccine strains, and the capripoxvirus assay targets the conserved P32 gene. The assays proved highly sensitive and specific. The set of PCRs was validated against a panel of 596 samples collected in the field, including whole blood, serum, skin lesions, nasal and ocular discharge, milk, lymph nodes, lungs, trachea, spleen and aborted calves. Using the assays reported here some samples obtained as part of national surveillance for LSD virus from animals exhibiting clinical signs consistent with LSDV turned out to be positive for vaccine LSD virus genome in 2017. This vaccine strain is highly likely to have derived from commercial live-attenuated vaccines against LSD virus. The way of introduction of a vaccine LSD 
virus strain into Russian cattle remains to be investigated.

Keywords: lumpy skin disease, vaccine, diagnostics, real-time PCR, genome, virus.

\section{R E F E R E N C E S}

1. Coetzer J.A.W. Lumpy skin disease. In: Infectious diseases of livestock. J.A.W. Coetzer, R.C. Tustin (eds.). Oxford University Press, Cape Town, 2004.

2. Hunter P., Wallace D. Lumpy skin disease in southern Africa: a review of the disease and aspects of control. Journal of the South African Veterinary Association, 2001, 72: 68-71 (doi: 10.4102/jsava.v72i2.619).

3. Woods J.A. Lumpy skin disease: a review. Tropical Animal Health and Production, 1988, 20(1): 11-17.

4. Sameea Yousefi P., Mardani K., Dalir-Naghadeh B., Jalilzadeh-Amin G. Epidemiological study of lumpy skin disease outbreaks in North-western Iran. Transboundary and Emerging Diseases, 2016, 64(6): 1782-1789 (doi: 10.1111/tbed.12565).

5. Buller R.M., Arif B.M., Black D.N., Dumbell K.R., Esposito J.J., Lefkowitz E.J., McFadden G., Moss B., Mercer A.A., Moyer R.W., Skinner M.A., Tripathy D.N. Family Poxviridae. In: Virus taxonomy: classification and nomenclature of viruses. Eighth Report of the International Committee on Taxonomy of Viruses. C.M. Fauquet, M.A. Mayo, J. Maniloff, U. Desselberger, L.A. Ball (eds.). Elsevier Academic Press, San Diego, 2005.

6. Tulman E.R., Afonso C.L., Lu Z., Zsak L., Kutish G.F., Rock D.L. Genome of lumpy skin disease virus. Journal of Virology, 2001, 75(15): 7122-7130 (doi: 10.1128/JVI.75.15.7122-7130.2001).

7. Elhaig M.M., Selim A., Mahmoud M. Lumpy skin disease in cattle: frequency of occurrence in a dairy farm and a preliminary assessment of its possible impact on Egyptian buffaloes. Onderstepoort Journal of Veterinary Research, 2017, 84(1): e1-e6 (doi: 10.4102/ojvr.v84i1.1393).

8. Gomo C., Kanonhuwa K., Godobo F., Tada O., Makuza S.M. Temporal and spatial distribution of lumpy skin disease (LSD) outbreaks in Mashonaland West Province of Zimbabwe from 2000 to 2013. Tropical Animal Health and Production, 2017, 49(3): 509-514 (doi: 10.1007/s11250-0171222-y).

9. Swiswa S., Masocha M., Pfukenyi D.M., Dhliwayo S., Chikerema S.M. Long-term changes in the spatial distribution of lumpy skin disease hotspots in Zimbabwe. Tropical Animal Health and Production, 2017, 49(1): 195-199 (doi: 10.1007/s11250-016-1180-9).

10. Zeynalova S., Asadov K., Guliyev F., Vatani M., Aliyev V. Epizootology and molecular diagnosis of lumpy skin disease among livestock in Azerbaijan. Frontiers in Microbiology, 2016, 7: 1022 (doi: 10.3389/fmicb.2016.01022).

11. Carn V.M., Kitching R.P. An investigation of possible routes of transmission of lumpy skin disease virus (Neethling). Epidemiology \& Infection, 1995, 114: 219-226 (doi: 10.1017/S0950268800052067).

12. Chihota C.M., Rennie L.F., Kitching R.P., Mellor P.S. Mechanical transmission of lumpy skin disease virus by Aedes aegypti (Diptera: Culicidae). Epidemiology \& Infection, 2001, 126: 317-321 (doi: 10.1017/S0950268801005179).

13. Lubinga J.C., Tuppurainen E.S., Coetzer J.A., Stoltsz W.H., Venter E.H. Transovarial passage and transmission of LSDV by Amblyomma hebraeum, Rhipicephalus appendiculatus and Rhipicephalus decoloratus ticks. Experimental and Applied Acarology, 2014, 62(1): 67-75 (doi: 10.1007/s10493-013-9722-6).

14. Tuppurainen E.S., Venter E.H., Coetzer J.A., Bell-Sakyi L. Lumpy skin disease: attempted propagation in tick cell lines and presence of viral DNA in field ticks collected from naturally-infected cattle. Ticks and Tick-borne Diseases, 2015, 6(2): 134-140 (doi: 10.1016/j.ttbdis.2014.11.002).

15. Tasioudi K.E., Antoniou S.E., Iliadou P., Sachpatzidis A., Plevraki E., Agianniotaki E.I., Fouki C., Mangana-Vougiouka O., Chondrokouki E., Dile C. Emergence of lumpy skin disease in Greece, 2015. Transboundary and Emerging Diseases, 2016, 63(3): 260-265 (doi: 10.1111/tbed.12497).

16. Carn V.M., Kitching R.P. An investigation of possible routes of transmission of lumpy skin disease virus (Neethling). Epidemiology and Infection, 1995, 114(1): 219-226.

17. Alkhamis M.A., Vander Waal K. Spatial and temporal epidemiology of lumpy skin disease in the Middle East, 2012-2015. Frontiers in Veterinary Science, 2016, 3: 19 (doi: 10.3389/fvets.2016.00019).

18. Mercier A., Arsevska E., Bournez L., Bronner A., Calavas D., Cauchard J., Falala S., Caufour P., Tisseuil C., Lefrançois T., Lancelot R. Spread rate of lumpy skin disease in the Balkans, 2015-2016. Transboundary and Emerging Diseases, 2017, 65: 240-243 (doi: 10.1111/tbed.12624).

19. Abutarbush S.M., Ababneh M.M., Al Zoubi I.G., Al Sheyab O.M., Al Zoubi M.G., Alekish M.O., Al Gharabat R.J. Lumpy skin disease in Jordan: disease emergence, clinical signs, complications and preliminary-associated economic losses. Transboundary and Emerging Diseases, 2015, 62(5): 549-554 (doi: 10.1111/tbed.12177).

20. Biryuchenkova M.V., Timina A.M, Zinyakov N.G., Shcherbakov A.V.. Veterinariya segodnya, 2015, 4(15): 43-45 (in Russ.).

21. Sprygin A., Artyuchova E., Babin Y., Prutnikov P., Kostrova E., Byadovskaya O., Kononov A. 
Epidemiological characterization of lumpy skin disease outbreaks in Russia in 2016. Transboundary and Emerging Diseases, 2018, 65(6): 1514-1521 (doi: 10.1111/tbed.12889).

22. OIE. Follow-up report No. 20. Report Date: 28/12/2018. Available http://www.oie.int/wahis_2/temp/reports/en_fup_0000029055_20181228_142744.pdf. No date.

23. Bedeković T., Šimić I., Krešić N., Lojkić I. Detection of lumpy skin disease virus in skin lesions, blood, nasal swabs and milk following preventive vaccination. Transboundary and Emerging Diseases, 2018, 65(2): 491-496 (doi: 10.1111/tbed.12730).

24. Kononov A., Prutnikov P., Shumilova I., Kononova S., Nesterov A., Byadovskaya O., Pestova Y., Diev V., Sprygin A1. Determination of lumpy skin disease virus in bovine meat and offal products following experimental infection. Transboundary and Emerging Diseases, 2019, 00: 1-9 (doi: 10.1111/tbed.13158).

25. Tuppurainen E.S., Venter E.H., Shisler J.L., Gari G., Mekonnen G.A., Juleff N., Lyons N.A., De Clercq K., Upton C., Bowden T.R., Babiuk S., Babiuk L.A. Capripoxvirus diseases: current status and opportunities for control. Transboundary and Emerging Diseases, 2017, 64(3): 729-745 (doi: 10.1111/tbed.12444).

26. Bedeković T., Šimić I., Krešić N., Lojkić I. Detection of lumpy skin disease virus in skin lesions, blood, nasal swabs and milk following preventive vaccination. Transboundary and Emerging Diseases, 2018, 65(2): 491-496 (doi: 10.1111/tbed.12730).

27. Pestova Ya.E, Artyukhova E.E., Kostrova E.E, Shumilova I.N., Kononov A.V., Sprygin A.V. Real time PCR for the detection of field isolates of lumpy skin disease virus in clinical samples from cattle. Agricultural Biology [Sel'skokhozyaistvennaya Biologiya], 2018, 53(2): 422-429 (doi: 10.15389/agrobiology.2018.2.422eng).

28. Lin L.I. A concordance correlation coefficient to evaluate reproducibility. Biometrics, 1989, 45(1): 255-268 (doi: 10.2307/2532051)

29. Ireland D.C., Binepal Y.S. Improved detection of capripoxvirus in biopsy samples by PCR. Journal of Virological Methods, 1998, 74(1): 1-7 (doi: 10.1016/S0166-0934(98)00035-4).

30. Stubbs S., Oura C.A., Henstock M., Bowden T.R., King D.P., Tuppurainen E.S. Validation of a high-throughput real-time polymerase chain reaction assay for the detection of capripoxviral DNA. Journal of Virological Methods, 2012, 179(2): 419-422 (doi: 10.1016/j.jviromet.2011.11.015).

31. Vidanovic D., Sekler M., Petrovic T., Debekjak Z., Vaskovic N., Matovic K., Hoffmann B. Real-time PCR assays for the species detection of field Balkan strains of lumpy skin disease virus. Acta Veterinaria Belgrade, 2016, 66(4): 444-454 (doi: 10.1515/acve-2016-0038).

32. Agianniotaki E.I., Chaintoutis S.C., Haegeman A., Tasioudi K.E., De Leeuw I., Katsoulos P.D., Sachpatzidis A., De Clercq K., Alexandropoulos T., Polizopoulou Z.S., Chondrokouki E.D., Dovas C.I. Development and validation of a TaqMan probe-based real-time PCR method for the differentiation of wild type lumpy skin disease virus from vaccine virus strains. Journal of Virological Methods, 2017, 249: 48-57 (doi: 10.1016/j.jviromet.2017.08.011).

33. Babiuk S., Bowden T.R., Parkyn G., Dalman B., Manning L., Neufeld J., Embury-Hyatt C., Copps J., Boyle D.B. Quantification of lumpy skin disease virus following experimental infection in cattle. Transboundary and Emerging Diseases, 2008, 55(7): 299-307 (doi: 10.1111/j.18651682.2008.01024.x).

34. Sprygin A., Pestova Y., Prutnikov P., Kononov A. Detection of vaccine-like lumpy skin disease virus in cattle and Musca domestica L. flies in an outbreak of lumpy skin disease in Russia in 2017. Transboundary and Emerging Diseases, 2018, 65(5): 1137-1144 (doi: 10.1111/tbed.12897).

35. Sprygin A.V, Kononov A.V., B'yadovskaya O.P. et al. Oligonukleotidnye praimery i fluorestsentno-mechenyi zond, sposob $i$ test-sistema PTSR $v$ rezhime real'nogo vremeni dlya vyyavleniya genoma kapripoksvirusov. Pat. 2658493, FGBU «Federal'nyi tsentr okhrany zdorov'ya zhivotnykh» (FGBU «VNIIZZH»). № 2017130118. Zayavl. 24.08.2017. Opubl. 21.06.2018. Byul. № 18 [Oligonucleotide primers and labeled fluorescent probe, method and real-time PCR test system for detecting the genome of capripoxviruses. No. 2017130118. Appl. 24.08.2017. Publ. 21.06.2018. Bul. No. 18] (in Russ.).

36. Sprygin A.V, Kononov A.V., B'yadovskaya O.P. et al. Oligonukleotidnye praimery i fluorestsentno-mechenyi zond, sposob $i$ test-sistema dlya vyyavleniya genoma polevykh izolyatov virusa zaraznogo uzelkovogo dermatita (nodulyarnogo dermatita) KRS v reaktsii polimeraznoi tsepnoi reaktsii $v$ rezhime real'nogo vremeni. Pat. 2668398, FGBU «Federal'nyi tsentr okhrany zdorov'ya zhivotnykh» (FGBU «VNIIZZH»). № 2017124318. Zayavl. 07.07.2017. Opubl. 28.09.2018. Byul. № 28 [Oligonucleotide primers and labeled fluorescent probe, method and test system for detecting the genome of field isolates of infectious nodular dermatitis virus (nodular dermatitis) of cattle in real-time polymerase chain reaction. No. 2017124318. Appl. 07.07.2017. Publ. 28.09.2018. Bul. No. 6] (in Russ.). 